\title{
Upconverting nanoparticle reporter-based highly sensitive rapid lateral flow immunoassay for hepatitis B virus surface antigen
}

\author{
lida Martiskainen ${ }^{1} \cdot$ Sheikh M. Talha ${ }^{1} \cdot$ Karoliina Vuorenpää $^{1} \cdot$ Teppo Salminen $^{1}$ • Etvi Juntunen ${ }^{1}$. \\ Souvick Chattopadhyay ${ }^{2}$. Dinesh Kumar ${ }^{3} \cdot$ Tytti Vuorinen $^{4} \cdot$ Kim Pettersson $^{1} \cdot$ Navin Khanna $^{5} \cdot$ Gaurav Batra $^{2}$ (D)
}

Received: 22 August 2020 /Revised: 22 October 2020 / Accepted: 9 November 2020 / Published online: 23 November 2020

(C) The Author(s) 2020

\begin{abstract}
Detection of hepatitis B Virus surface antigen (HBsAg) is an established method for diagnosing both acute and chronic hepatitis $\mathrm{B}$ virus (HBV) infection. In addition to enzyme immunoassays (EIAs), rapid diagnostic tests (RDTs) are available for the detection of HBsAg in resource-poor settings. However, the available RDTs have inadequate sensitivity and therefore are not suitable for diagnosis of patients with low levels of HBsAg and for blood screening. To provide a high-sensitivity RDT, we developed a lateral flow immunoassay (LFIA) for HBsAg utilizing upconverting nanoparticle (UCNP) reporter. The UCNPLFIA can use whole blood, serum, or plasma and the results can be read in 30 min using a reader device. When compared with a commercial conventional visually read LFIA, the developed UCNP-LFIA had a Limit of Detection (LoD) of $0.1 \mathrm{IU} \mathrm{HBsAg} / \mathrm{ml} \mathrm{in}$ spiked serum, whereas the LoD of the conventional LFIA was $3.2 \mathrm{IU} \mathrm{HBsAg} / \mathrm{ml}$. The developed UCNP-LFIA fulfills the WHO criterion for blood screening (LoD $\leq 0.13 \mathrm{IU} \mathrm{HBsAg} / \mathrm{ml}$ ) in terms of LoD. The UCNP-LFIA and conventional LFIA were evaluated with well-characterized sample panels. The UCNP-LFIA detected 20/24 HBsAg-positive samples within the HBsAg Performance Panel and 8/10 samples within the Mixed Titer Performance Panel, whereas the conventional LFIA detected 8/24 and 4/10 samples in these panels, respectively. The performance of the assays was further evaluated with HBsAg-positive $(n=$ $108)$ and HBsAg-negative $(n=315)$ patient samples. In comparison with a central laboratory test, UCNP-LFIA showed $95.4 \%$ (95\% CI: 89.5-98.5\%) sensitivity whereas sensitivity of the conventional LFIA was 87.7\% (95\%CI: 79.9-93.3\%).
\end{abstract}

Keywords HBsAg $\cdot$ HBV diagnostics $\cdot$ Upconverting nanophosphors $\cdot$ Lateral flow $\cdot$ Point-of-care test

\section{Introduction}

Hepatitis B virus (HBV) can be transmitted through contact with infected blood or other body fluids as well as perinatally from infected mothers to neonates. There

Gaurav Batra

gaurav.batra@thsti.res.in

1 Department of Biotechnology, University of Turku, 20014 Turku, Finland

2 Translational Health Science and Technology Institute, NCR Biotech Science Cluster, Faridabad 121001, India

3 Arrow weighing systems Pvt Ltd (unit Designinnova), New Delhi 110028, India

4 Department of Virology and Clinical Microbiology, University of Turku, 20520 Turku, Finland

5 International Centre for Genetic Engineering \& Biotechnology, New Delhi 110067, India are around 257 million persons worldwide living with $\mathrm{HBV}$, and as per 2015 data, HBV infection resulted in around 887,000 deaths $[1,2]$.

$\mathrm{HBV}$ is a major health problem in low- and middle-income countries (LMIC) [3]. Worldwide, over $67 \%$ of chronically infected carriers of HBV are living in Asia and Africa. Prevalence is highest in the African (6.1\%) and Western Pacific regions (6.2\%) [1]. Many countries in these regions have HBV prevalence higher than $10 \%$.

Most of the infected individuals are asymptomatic at the early stage of infection. However, a small proportion of acute infections are symptomatic, and a very small proportion can develop acute liver failure. In some individuals, HBV can cause chronic liver infection which may result in cirrhosis and hepatocellular carcinoma leading to death [4].

Identification and treatment of asymptomatic people with chronic HBV infection should reduce the disease burden. However, HBV screening is non-existent in several LMIC and even the blood donor screening is performed using tests 
with inadequate sensitivity [5]. Only $10.5 \%$ of all chronically infected individuals are aware of their infection [2].

The recommended and most used method for the screening of HBV is serological testing of HBsAg [6]. Highly sensitive enzyme immunoassays (EIAs) can be used for reliable detection of HBsAg. However, EIAs require sophisticated laboratory infrastructure with trained personnel and have turnaround-times ranging from 3 to $5 \mathrm{~h}$. Moreover, because of the time gap between sampling and results, follow-up with the patient is often at risk. Rather than EIAs, rapid diagnostic tests (RDTs) like lateral flow immunoassays (LFIAs) provide an alternative for the detection of HBsAg as the RDTs can be used without laboratory infrastructure with minimal training. The greatest advantage of RDTs is their cost-efficiency and the turn-around-times of 15 to $30 \mathrm{~min}$.

RDTs are used for diagnostic purposes and even for the screening of blood donors in many resource-limited settings when EIAs are not feasible [7]. However, the performance of the RDTs used for the detection of HBsAg is often inferior compared with central laboratory tests. In Ghana, blood donor screening for HBsAg using RDT with a sensitivity of $7.5 \mathrm{IU} /$ $\mathrm{ml}$ revealed $8 \%$ prevalence. In the same population, a sensitive EIA with analytical sensitivity of $0.05 \mathrm{IU} / \mathrm{ml} \mathrm{HBsAg}$ revealed a prevalence of $14-15 \%$ [3]. The available data shows that the analytical sensitivity of most RDTs is in the range of $2-10 \mathrm{IU} / \mathrm{mL}$ which is approximately 50 - to 100 -fold less sensitive compared with widely used CE-marked EIAs $[8,9]$.

Screening of blood products for transfusion requires highsensitivity assays to detect low HBsAg levels for, e.g., those found in early seroconversion to minimize the risk of transfusion transmitted infection [9]. As per the World Health Organization (WHO) performance evaluation acceptance criteria for HBsAg test in the context of WHO Prequalification, an assay should have analytical sensitivity of $\leq 4 \mathrm{IU} / \mathrm{mL}$ to be used for routine diagnostic purposes and $\leq 0.13 \mathrm{IU} / \mathrm{ml}$ for the screening of blood donations [9].

The inadequate sensitivity of the typical lateral flow tests is affected by the relatively short incubation time for antigen and antibody interaction [10] and the inadequate signal generation strength of traditionally used visual labels such as colloidal gold and carbon nanoparticles [11]. Moreover, visual readout is associated with a risk of misinterpretation of the results particularly with equivocal samples. The subjectivity involved with interpretation of visual results can be removed by using a suitable reader device. However, use of a reader device alone does not improve the sensitivity of the assay. It has been reported earlier that the sensitivity of lateral flow assays can be improved by replacing the visual labels with fluorescent nanoparticle reporters $[12,13]$.

Upconverting nanoparticles (UCNP) have successfully been used as reporters in the development of highly sensitive lateral flow assays for the detection of wide range of target analytes including Schistosoma circulating anodic antigen
[14], hCG [15], IL-10 [16], cTnI [17], prostate-specific antigen [18], ephrin type-A receptor 2 [18], HBV nucleic acids, small molecules such as ochratoxin A, heavy metal ions $(\mathrm{Hg} 2+)$, and bacteria such as Salmonella [19]. Also, UCNP-LFIAs have been used for quantifying myoglobin [20] and for the measurement of anti-HBV surface antigen antibodies [21] among others.

UCNPs have a unique feature of converting lower energy excitation wavelength into higher energy emission at visible wavelengths [22]. Use of UCNP reporters can further enhance the assay sensitivity compared with traditional fluorescent labels since it eliminates the measurement background autofluorescence originating from the sample matrix or the components of the test device. This background elimination is due to the spectral separation of UCNP excitation, emission, and background autofluorescence wavelengths [23].

Here, we designed and produced a UCNP reporter-based LFIA (UCNP-LFIA) for high-sensitivity detection of HBsAg in serum, plasma, and whole blood. First, we generated monoclonal antibodies (mAbs) against HBsAg, selected the best pair of mAbs, and optimized the UCNP-LFIA components and assay conditions. The developed assay was evaluated using well-characterized panels of clinical samples, WHO International standard for HBsAg, genotype panels, and a seroconversion panel. In addition, the results were compared with a commercially available conventional HBsAg LFIA. UCNP-LFIA could achieve analytical sensitivity of $0.1 \mathrm{IU}$ $\mathrm{HBs} \mathrm{Ag} / \mathrm{ml}$ in serum compared with $3.2 \mathrm{IU} \mathrm{HBsAg} / \mathrm{ml}$ of the conventional LFIA.

\section{Materials and methods}

\section{Samples and reference assays}

WHO Third International Standard for HBsAg (12/226) was purchased from the National Institute for Biological Standards and Controls (NIBSC, United Kingdom). The 1st WHO International Reference Panel for Hepatitis B Virus (HBV) Genotypes for Hepatitis B Surface Antigen (HBsAg) Assays (6100/09) was purchased from PaulEhrlich Institute (Germany).

The following commercial sample panels were purchased from SeraCare Life Sciences Inc. (MA, USA): AccuSet ${ }^{\mathrm{TM}}$ HBsAg Performance Panel (0805-0340), AccuSet ${ }^{\mathrm{TM}} \mathrm{HBsAg}$ Mixed Titer Performance Panel PHA207(M) (0805-0217), AccuSet ${ }^{\mathrm{TM}}$ HBV Worldwide Performance Panel (08050313), HBV Seroconversion Panel PHM941 (0606-0060) and $24 \mathrm{HBsAg-positive} \mathrm{disease-state} \mathrm{samples.} \mathrm{These} \mathrm{panels}$ consist of undiluted, naturally occurring plasma samples. Fifty HBsAg-positive serum samples were purchased from Biomex $\mathrm{GmbH}$ (Germany). Eighteen HBsAg-positive plasma samples were purchased from Labquality Oy (Finland). Whole blood 
and serum used for international standard's dilutions, as well as a sample panel consisting of 100 presumed HBsAgnegative serum samples, were purchased from Turku University of Applied Sciences (Finland).

Apart from commercially available sample panels, 215 clinical serum and plasma samples that tested negative for HBsAg and 16 samples that tested positive for HBsAg were obtained from the Department of Virology, University of Turku (Finland). All the patient data, except for the status for the presence or absence of HBsAg, were anonymized and no clinical data of the patients were handled. Use of these samples in this study was approved by the Ethical Committee of the Hospital District of Southwest Finland (Decision T012/ 011/18). The details of the reference tests used for the characterization of these samples are summarized in Table S1 (see Electronic Supplementary Material, ESM). Assay principle for the central laboratory reference tests is described in the ESM.

Apart from using central laboratory tests as reference, a commercially available conventional rapid LFIA (Alere DetermineTM HBsAg (code \# 7D2543), Abbott Laboratories, USA) based on visual detection of signals was used for comparison.

\section{Anti-HBsAg antibodies}

Mouse monoclonal antibodies against $\mathrm{HBsAg}$ were generated using hybridoma technology [24].

\section{Bioconjugation of UCNP reporters}

Carboxylated Upcon ${ }^{\mathrm{TM}}$ UCNP reporter particles of 68-nm diameter with a hydrophilic coating (Kaivogen Oy, Finland) were covalently coupled with an in-house mouse antiHBsAg monoclonal antibody (mAb) 3D3. A solution containing $1 \mathrm{mg}$ UCNPs was centrifuged, the supernatant was removed, and the particle surface was activated by suspending the pellet into particle activation buffer ( $20 \mathrm{mM}$ MES pH 6.1, $2 \mathrm{mM} \mathrm{KF}, 20 \mathrm{mM}$ EDC, and $30 \mathrm{mM}$ sulfo-NHS). The incubation was performed with rotation for $15 \mathrm{~min}$ at room temperature. The UCNPs were washed by centrifugation, removing the supernatant and suspending the UCNPs to $20 \mathrm{mM}$ MES, pH 6.1. The UCNPs were centrifuged as before and resuspended into $20 \mathrm{mM}$ MES, $\mathrm{pH} 6.1$ containing $84 \mu \mathrm{g}$ of $\mathrm{mAb} 3 \mathrm{D} 3$. This conjugation reaction was incubated for $2.5 \mathrm{~h}$ at room temperature with rotation and the reaction was stopped by adding glycine, $\mathrm{pH} 11$. To remove noncovalently associated $\mathrm{mAb}$, the UCNP conjugates were washed twice by centrifugation and the pellet was suspended in $500 \mu$ lof storage buffer ( $5 \mathrm{mM}$ Tris, $0.05 \% \mathrm{NaN} 3,0.05 \%$ Tween-85, pH 8.5). This step was repeated twice, and finally, the pellet was suspended to $250 \mu \mathrm{l}$ of storage buffer and BSA was added to a final concentration of $0.5 \%$.

\section{Preparation of LFIA strips}

A lateral flow card was assembled on a plastic backing by pasting nitrocellulose membrane 200CNPH-N-SS60 (Advanced Microdevices Pvt. Ltd., India), a cellulose absorbent pad (CFSP223000, Merck Millipore, MA, USA), a glass fiber conjugate pad (8951, Ahlstrom-Munksjö Oyj, Finland), and a red blood cell separator sample pad (FR1 0.6, Advanced Microdevices Pvt. Ltd., India). The sample pad was pretreated with blocking buffer solution $(10 \mathrm{mM}$ Tris-HCl pH 8.5, $135 \mathrm{mM} \mathrm{NaCl}, 0.5 \%$ Tween-20, $0.1 \%$ Triton-X$100,0.8 \mathrm{mg} / \mathrm{ml}$ mouse $\mathrm{IgG}, 0.2 \%$ denatured mouse IgG, $0.24 \%$ bovine $\operatorname{IgG}$ ). The test line solution consisted of equal proportions of three anti-HBsAg mAbs. Two of these mAbs were in-house (mAb 3G8 and mAb 4G9) and one was procured from a commercial source (mAb 2508 SPTN-5, Medix Biochemica $\mathrm{Oy} \mathrm{Ab}$, Finland). The line dispensing was performed in $10 \mathrm{mM}$ Tris- $\mathrm{HCl}$, $\mathrm{pH} 8.0$ buffer on the nitrocellulose membrane at a concentration of $300 \mathrm{ng} / \mathrm{cm}$. The control line was printed $4 \mathrm{~mm}$ from the test line with $300 \mathrm{ng} / \mathrm{cm}$ of rabbit anti-mouse IgG (Dako Products, Agilent Technologies Inc., USA). After printing test and control lines, the cards were dried overnight at $+35^{\circ} \mathrm{C}$, other components of the test strips were assembled, and the cards were stored at room temperature protected from humidity. The cards were covered with transparent cover tape (KN-CPP1-Clear Kenosha cover plastic, Kenosha, Netherlands) starting from the conjugate pad to the end of the absorbent pad. Before the use, the cards were cut into $4.8-\mathrm{mm}$-wide strips. Twenty nanograms of UCNP reporters were dried onto the conjugate pad of each of the strip in $10 \mathrm{mM}$ Tris-HCl buffer, $\mathrm{pH} 8.5$ containing $135 \mathrm{mM} \mathrm{NaCl}$, $0.5 \%$ Tween-20, $1 \%$ BSA, $5 \%$ sucrose. The strips were dried protected from humidity. The strips were placed in a suitable plastic housing with a common inlet for sample and buffer.

\section{UCNP-LFIA procedure}

To start the procedure, $50 \mu \mathrm{l}$ of the sample was added into the sample inlet, followed by applying $50 \mu \mathrm{l}$ of chase buffer (10 mM Tris- $\mathrm{HCl} \mathrm{pH} 8.5,135 \mathrm{mM} \mathrm{NaCl}, 0.5 \%$ Tween-20, $1 \%$ BSA, and $0.1 \%$ Triton-X-100). After $30 \mathrm{~min}$, the test and control line upconversion photoluminescence signals were measured with an Upcon reader device (Labrox Oy, Finland) with excitation at $976 \mathrm{~nm}$ and emission at $550 \mathrm{~nm}$. Details of the benchtop UCNP reader and a battery-operated portable UCNP reader are provided in the ESM (Fig. S10).

The interpretation of the results was based on the maximum signal measured at the test line position. The overall baseline signal measured along the strip was subtracted from the test line maximum signal. Thus, only the test line peak signal was considered the outcome of the measurement. The control line signals were interpreted as qualitative control. 


\section{Add $50 \mu$ sample
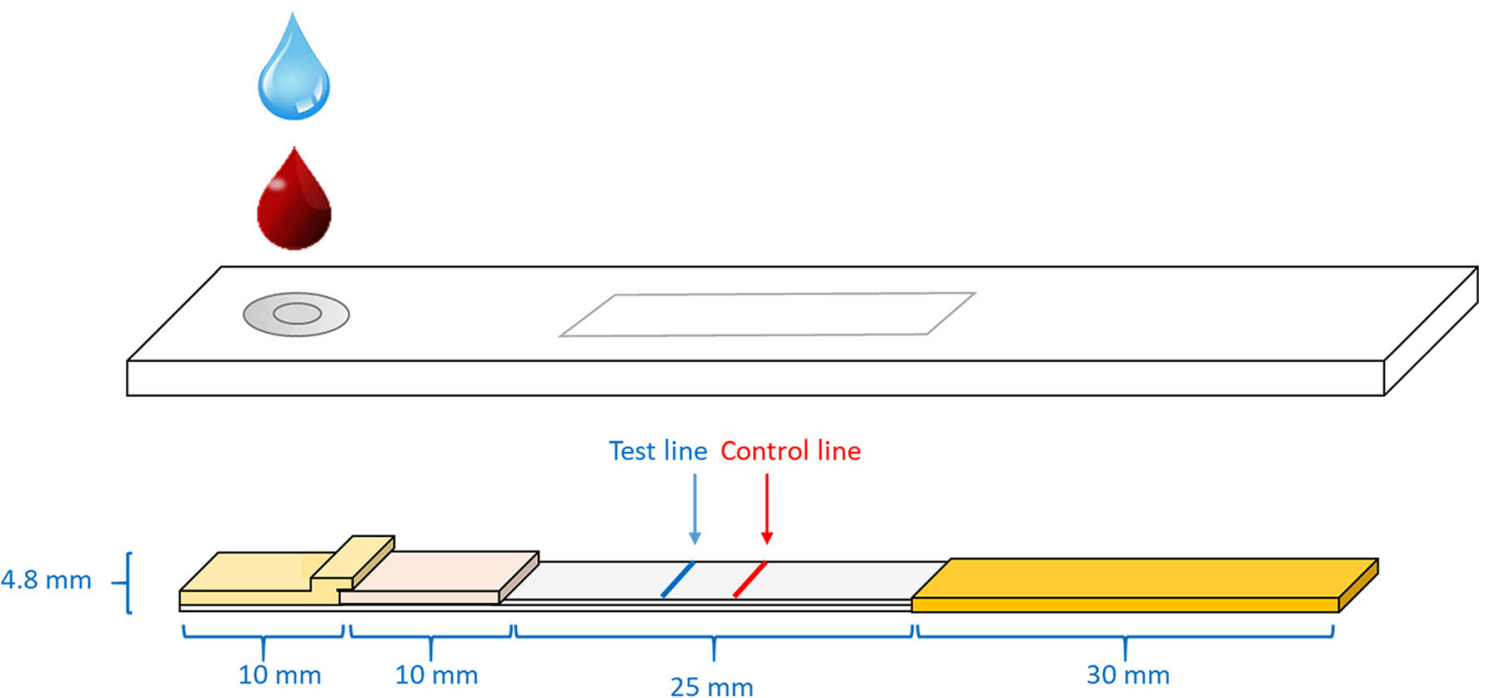

Fig. 1 UCNP-LFIA strip design and assay procedure. The strip consisted, from left to right, of a sample pad, a conjugate release pad, a nitrocellulose analytical membrane, and an absorbent pad inside a plastic housing. The assay procedure was started by adding $50 \mu$ of sample to

\section{Limit of detection}

Two methods were used for determining the limit of detection (LoD), both in serum and in whole blood. In the first method, dilutions of the WHO Third International Standard for HBsAg between 0.01 and $12.8 \mathrm{IU} / \mathrm{ml}$ were used for plotting standard curves. For the standard curve, 20 replicates were used for each of the three low concentration dilutions $(0.05,0.1$, and $0.2 \mathrm{IU} / \mathrm{ml})$ near the pre-estimated detection limit. Four replicate strips were used for the other concentrations.

The cutoff level for the LoD was determined by using 60 replicates of the blank sample and selecting the highest measured signal value from these replicates as the cutoff value. The $\mathrm{LoD}(\mathrm{IU} / \mathrm{ml})$ was calculated from the cutoff and the equation obtained with linear regression of the standard curve.

The LoD was further confirmed with a second method by performing an additional test using 80 replicates of the three concentrations below, above, and at the same level $(0.05,0.1$, and $0.2 \mathrm{IU} / \mathrm{ml}$ ) as the previously calculated LoD. The sample size of 80 was based on a statistical sampling plan (ISO 2859-1:1999) previously used by Das et al. [25]. Sample size code J was determined by using general inspection level II and was based on a lot size of 501-1200. A single sampling plan for normal inspection was used, which resulted in a sample size of 80 .

The LoD of conventional HBsAg LFIA (Alere DetermineTM HBsAg) was determined similarly with the WHO third international standard for HBsAg. The standard was diluted in serum in concentrations of $0.8,1.6,3.2,4.8$, the sample pad followed by $50 \mu \mathrm{l}$ of chase buffer. The UCNP signal was measured after $30 \mathrm{~min}$ with a reader device. UCNP signal profile of strips is provided in ESM (Fig. S11)

6.4, and $12.8 \mathrm{IU} / \mathrm{ml}$. Dilutions were run on the commercial RDT, in 4 replicates for concentrations $0.8-6.4 \mathrm{IU} / \mathrm{ml}$, and two replicates for concentration $12.8 \mathrm{IU} / \mathrm{ml}$, according to the manufacturer's instructions. The visual results were interpreted by two individuals.

\section{Assay performance evaluation}

All the clinical samples and sample panels were evaluated with the developed assay according to the UCNP-LFIA procedure. All the clinical serum and plasma samples from different individuals not belonging to a commercial fixed sample panel (e.g., performance panel, mixed titer panel) were used for determining the sensitivity and specificity of the assay. The total sample numbers used for the calculation of the assay performance were 108 HBsAg-positive and $315 \mathrm{HBsAg-negative} \mathrm{samples.}$

The optimal clinical cutoff value was determined based on receiver operating characteristic (ROC) analysis executed by SAS JMP Pro 14 statistics software. To calculate the signal-tocutoff ( $\mathrm{S} / \mathrm{Co})$, photoluminescence signal obtained from each sample with peak detection was divided by the cutoff. Samples with $\mathrm{S} / \mathrm{Co}$ values $\geq 1$ were considered reactive.

In order to compare the performance of the developed assay with a conventional HBsAg rapid LFIA, all the clinical samples were tested with commercial RDT according to the manufacturer's instructions. The visual results were interpreted by two individuals who were blinded for the reference assay results. 

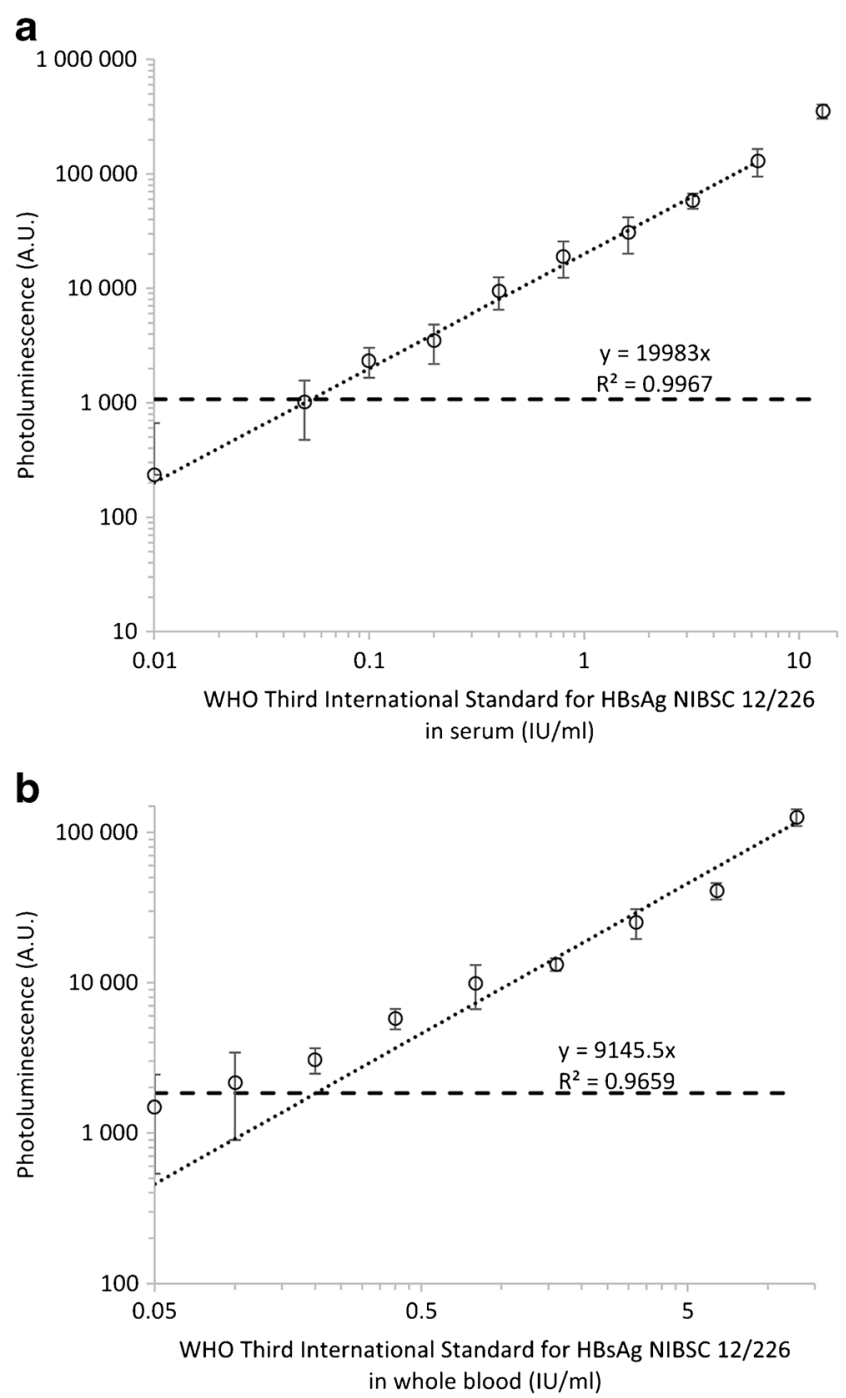

Fig. 2 Limit of detection of the developed LFIA in A human serum and $\mathbf{B}$ human whole blood by using WHO third international standard for HbsAg (NIBSC 12/226). The cutoff level is shown with the dashed line. Based on the curve, the LoD in serum was $0.05 \mathrm{HBsAg} \mathrm{IU} / \mathrm{ml}$ and in whole blood $0.2 \mathrm{HBsAg} \mathrm{IU/ml}$

\section{UCNP-LFIA strip stability study}

The strips were stored in sealed aluminum foil pouches with a desiccant at $+37{ }^{\circ} \mathrm{C}$ for 50 days. The strip stability was studied at 7 time points during this period by testing the strips with the UCNP-LFIA procedure. Native HBsAg protein (Yashraj Biotechnology Ltd., India) was diluted in HBsAg-negative human serum in concentrations of $0,0.5$, and $5 \mathrm{ng} / \mathrm{ml}$ and used as a sample.

\section{Photoluminescence measurement reproducibility}

Dry strips assayed with human serum spiked with $0,0.5$, and $5 \mathrm{ng} / \mathrm{ml}$ HBsAg were measured 15 times. The measurement reproducibility was determined by calculating the coefficient of variation between repeat measurements of the same strip.

\section{Results and discussion}

The objective of the work was to develop an ultra-sensitive RDT that can bridge the sensitivity gap between conventional RDTs and the more complicated and resource-demanding EIAs for the detection of HBsAg. The developed RDT was a LFIA with a simple assay procedure (Fig. 1).

\section{Design and development of UCNP-LFIA for HBsAg}

We developed the LFIA using UCNP reporter particles for the detection of HBsAg. The assay development and optimization included hybridoma antibody generation (ESM Fig. S1), identification of most optimal conjugate antibody (ESM Fig. S2), epitope binning (ESM Fig. S3, Table S2), and antibody screening based on the binding with different HBV genotypes (ESM Fig. S4), identification of suitable antibody pair for the UCNP-LFIA (ESM Figs. S2, S5, and Table S3), drying of the UCNP conjugates (ESM Fig. S6), identification of nitrocellulose membrane and optimal time of measurement (ESM Table S4, Fig. S7), and sample volume optimization (ESM Fig. S8).

The obtained data suggested that mAb 3D3 as tracer in combination with mAbs 3G8, 2508, and 4G9 as capture was the most optimal antibody combination for the UCNP-LFIA. The mAb 3D3 was chosen as tracer mAb based on signal and background levels obtained in the UCNP-LFIA, and also based on the conjugate colloidal properties. Based on epitope

Table 1 Verification of the limit of detection of the developed LFIA by using WHO third international standard for HBsAg (NIBSC 12/226)

\begin{tabular}{|c|c|c|c|}
\hline \multirow{2}{*}{$\begin{array}{l}\text { WHO Third } \\
\text { International } \\
\text { Standard for } \\
\text { HBsAg, NIBSC } \\
12 / 226(\mathrm{IU} / \mathrm{ml})\end{array}$} & \multicolumn{2}{|l|}{ UCNP-LFIA } & \multirow{2}{*}{$\begin{array}{l}\text { Alere Determine } \\
\text { HBsAg } \\
\text { Diluted in serum }\end{array}$} \\
\hline & $\begin{array}{l}\text { Diluted in } \\
\text { serum }(\%)\end{array}$ & $\begin{array}{l}\text { Diluted in whole } \\
\text { blood }(\%)\end{array}$ & \\
\hline 0.01 & $0 / 4(0)$ & $0 / 4(0)$ & \\
\hline 0.05 & $61 / 80(76.3)$ & $3 / 20(15.0)$ & \\
\hline 0.1 & $79 / 80(98.8)$ & $9 / 20(45.0)$ & \\
\hline 0.2 & 20/20 (100) & $70 / 80(87.5)$ & \\
\hline 0.4 & 4/4 (100) & 4/4 (100) & \\
\hline 0.8 & 4/4 (100) & 4/4 (100) & $0 / 4$ \\
\hline 1.6 & 4/4 (100) & 4/4 (100) & $0 / 4$ \\
\hline 3.2 & 4/4 (100) & 4/4 (100) & $4 / 4$ \\
\hline 6.4 & 4/4 (100) & 4/4 (100) & $4 / 4$ \\
\hline 12.8 & 4/4 (100) & 4/4 (100) & $2 / 2$ \\
\hline
\end{tabular}




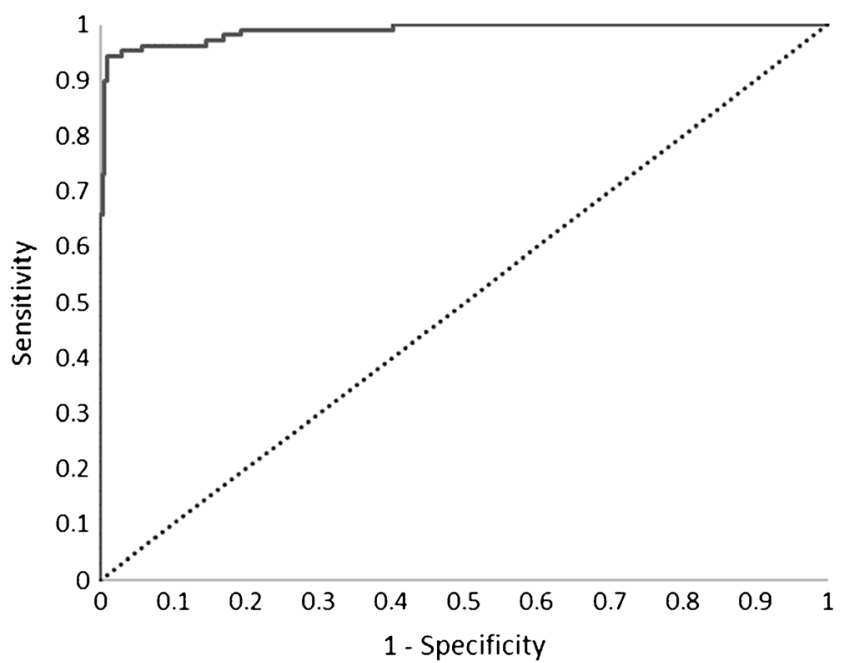

Fig. 3 Diagnostic accuracy of UCNP-LFIA. Receiver operating characteristic (ROC) of the UCNP-LFIA was calculated based on 108 HBsAg positive and $315 \mathrm{HBsAg}$-negative samples. The area under the curve (AUC) was 0.989

binning and evaluation of the genotype detection, we chose three non-competing capture antibodies. The antibodies were chosen based on their likelihood of binding to different epitopes on HBsAg (ESM Fig. S5) in order to reduce the risk of UCNP-LFIA missing HBsAg mutants. The MAb 3D3-UCNP conjugate was dried to the conjugate pad during the assay development phase. No difference between dry and liquid conjugates was observed (ESM Fig. S6). Optimal nitrocellulose membrane (CNPH-N SS60) and read time (30 min) were chosen based on the maximum signal difference between positive and negative spiked whole blood samples (ESM Fig. S7). An increase in sample volume to $50 \mu \mathrm{l}$ resulted in higher specific signals (ESM Fig. S8) and was chosen for further work.

\section{Determination of the limit of detection}

The LoD of the developed LFIA was determined in both serum and whole blood with WHO Third International Standard for HBsAg. The initial LoD calculated against the standard curve generated using serial dilution of international standard was $0.05 \mathrm{IU} / \mathrm{ml}$ in serum (Fig. 2A). Similarly, the initial LoD in whole blood was $0.2 \mathrm{IU} / \mathrm{ml}$ from the standard curve (Fig. $2 \mathrm{~B})$. The $\mathrm{LoD}$ was further validated by testing additional replicates with $\mathrm{HBs} A g$ concentrations close to the detection limit. With the HBsAg concentration of 0.05 and $0.1 \mathrm{IU} / \mathrm{ml}$ in serum, the assay correctly detected 61 out of $80(76.3 \%)$ and 79 out of $80(98.8 \%)$ replicate strips, respectively (Table 1). This suggests that the correct LoD in serum for UCNP-LFIA should be $0.1 \mathrm{IU} / \mathrm{ml}$. In the whole blood samples, only 70 out of 80 replicates $(87.5 \%)$ scored positive at a concentration of $0.2 \mathrm{IU} / \mathrm{ml}$ (Table 1). The UCNP-LFIA strip profiles from LoD measurements are shown in ESM (Fig. S11). For the comparison, the LoD of the commercial Alere Determine HBsAg LFIA was also determined in serum and found to be $3.2 \mathrm{IU} / \mathrm{ml}$ (Table 1).

The obtained analytical sensitivity of $3.2 \mathrm{IU} \mathrm{HBsAg} / \mathrm{mL}$ for the Alere Determine HBsAg test is similar to the $\mathrm{LoD}$ reported $(2 \mathrm{IU} / \mathrm{mL})$ in the literature for this test [26]. Currently, poor analytical sensitivity is considered one of the key challenges in using RDTs in screening HBV infections [27]. According to the study by Scheiblauer et al., the detection limits of commercial HBsAg RDTs vary between 1.5$10 \mathrm{IU} / \mathrm{ml}$ [8]. According to the review by Khuroo et al. multiple tests had detection limit of $4 \mathrm{IU} / \mathrm{ml}$ [28]. Others have tried to increase the sensitivity of HBsAg LFIA by the use of a signal amplification system where a dual tracer is used [26], use of fluorescent nanoparticles [29], use of chemiluminescence with CdS nanowire (NW) photosensor [30], and use of self-assembled colloidal gold superparticles [31] and achieved LoDs of $0.5 \mathrm{IU} / \mathrm{mL}, 2.5 \mathrm{IU} / \mathrm{mL}, 0.5 \mathrm{ng} / \mathrm{mL}$ and $0.46 \mathrm{ng} / \mathrm{mL}$, respectively.

The analytical sensitivity obtained by us with the developed UCNP-LFIA was 15- to 100 -fold higher than the typical RDTs for HBsAg. The UCNP-LFIA showed 32fold higher analytical sensitivity compared with the Alere Determine HBsAg LFIA that was tested in parallel. The
Table 2 Assay performances with clinical patient samples compared between the developed LFIA and Alere Determine HBsAgTM

\begin{tabular}{lll}
\hline & HBsAg LFIA & Alere Determine HBsAg \\
\hline Number of positive samples tested & 108 & 106 \\
Number of negative samples tested & 315 & 315 \\
Number of samples with agreeing result (with central lab tests) & \\
True positive & 103 & 93 \\
True negative & 306 & 314 \\
Number of samples with disagreeing result (with central lab tests) & \\
False positive & 9 & 1 \\
False negative & 5 & 13 \\
Sensitivity & $95.4 \%$ (95\%CI 89.5-98.5\%) & $87.7 \%$ (95\%CI 79.9-93.3\%) \\
Specificity & $97.1 \%(95 \%$ CI 94.7-98.7\%) & $99.7 \%$ (95\%CI 98.2-100\%) \\
Total number of tested samples & 423 & 421
\end{tabular}


Table 3 Evaluation of the developed UCNP-LFIA with AccuSet HBsAg Performance Panel and comparison with commercial RDT

\begin{tabular}{|c|c|c|c|}
\hline $\begin{array}{l}\text { Panel } \\
\text { member }\end{array}$ & $\begin{array}{l}\text { Abbott ARCHITECT } \\
\text { HBsAg (S/Co) }\end{array}$ & UCNP-LFIA (S/Co $)^{2}$ & $\begin{array}{l}\text { Alere Determine }{ }^{\mathrm{TM}} \text { HBsAg } \\
\text { result }^{3}\end{array}$ \\
\hline 01 & 1724.8 & 18.8 & +++ \\
\hline 02 & 3751.9 & 44.6 & +++ \\
\hline 03 & 77.6 & 2.2 & - \\
\hline 04 & 562.7 & 10.9 & ++ \\
\hline 05 & 2.5 & 0.0 & - \\
\hline 06 & 5.0 & 0.4 & - \\
\hline 07 & 181.6 & 2.0 & $+/-$ \\
\hline 08 & 55.6 & 1.7 & - \\
\hline 09 & 4620.8 & 59.5 & +++ \\
\hline 10 & 35.7 & 2.2 & - \\
\hline 11 & 7.4 & 0.4 & - \\
\hline 12 & 343.1 & 10.9 & ++ \\
\hline 13 & 118.2 & 2.0 & - \\
\hline 14 & 4613.0 & 56.4 & +++ \\
\hline 15 & 4078.0 & 89.8 & +++ \\
\hline 16 & 5159.4 & 66.0 & +++ \\
\hline 17 & 5045.3 & 84.7 & - \\
\hline 18 & 101.6 & 8.3 & - \\
\hline 19 & 10.8 & 1.8 & - \\
\hline 20 & 32.2 & 7.2 & - \\
\hline 21 & 121.3 & 4.5 & - \\
\hline 22 & 1.9 & 0.7 & - \\
\hline 23 & 1.4 & 1.0 & - \\
\hline 24 & 6.7 & 1.2 & - \\
\hline 25 & 0.1 & 0.4 & - \\
\hline
\end{tabular}

Positive results are presented in gray background

${ }^{1}$ Results from the panel data sheet. $\mathrm{S} / \mathrm{Co}$ ratios $\geq 1.0$ are reactive

${ }^{2}$ For UCNP-LFIA, S/Co ratios $\geq 1.0$ are considered reactive

${ }^{3}$ Interpretation: +++ strong visible test line; ++ visible test line; + faint visible test line; \pm equivocal, - no visible test line

Table 4 Evaluation of the developed UCNP-LFIA with AccuSet HBsAg Mixed Titer Performance Panel and comparison with Alere Determine ${ }^{\mathrm{TM}}$ HBsAg

\begin{tabular}{|c|c|c|c|}
\hline Panel member & $\begin{array}{l}\text { Abbott ARCHITECT HBsAg } \\
(\mathrm{S} / \mathrm{Co})^{1}\end{array}$ & UCNP-LFIA $(\mathrm{S} / \mathrm{Co})^{2}$ & $\begin{array}{l}\text { Alere Determine } \\
\text { HBsAg result }^{3}\end{array}$ \\
\hline PHA207-01 & 4.2 & 1.0 & - \\
\hline PHA207-02 & 2.9 & 0.2 & - \\
\hline PHA207-03 & 0.5 & 0.2 & - \\
\hline PHA207-05 & 3.8 & 0.5 & - \\
\hline PHA207-07 & 15.0 & 1.0 & - \\
\hline PHA207-08 & 21.6 & 5.5 & + \\
\hline PHA207-09 & 33.2 & 1.4 & - \\
\hline PHA207-13 & 15.5 & 3.8 & - \\
\hline PHA207-14 & 33.5 & 30.2 & + \\
\hline PHA207-15 & 4784.0 & 67.1 & +++ \\
\hline PHA207-18 & 5439.3 & 37.0 & +++ \\
\hline PHA207-21 & 0.6 & 0.2 & - \\
\hline
\end{tabular}


Table 5 Evaluation of the developed UCNP-LFIA with HBV Seroconversion Panel and comparison with Alere Determine ${ }^{\mathrm{TM}} \mathrm{HBsAg}$

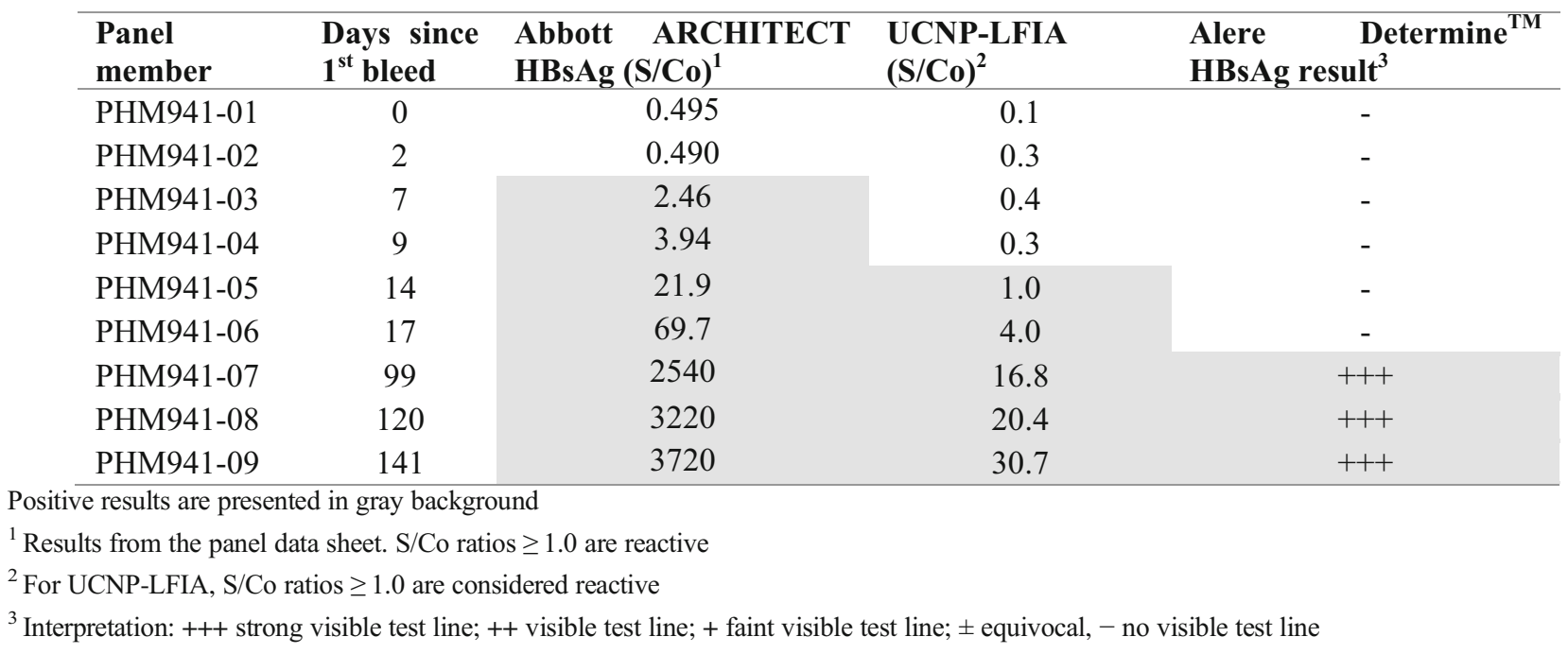

developed UCNP-LFIA would be suitable for diagnostic purposes in terms of the analytical sensitivity requirement of $\leq 4 \mathrm{IU} / \mathrm{ml}$ [9]. Moreover, based on the detection limit obtained in serum, the UCNP-LFIA may be suitable for screening of blood products according to the WHO criteria in terms of the analytical sensitivity requirement of $\leq 0.13 \mathrm{IU} / \mathrm{ml}[9]$.

\section{Evaluation of UCNP-LFIA using HBsAg-positive and HBsAg-negative samples}

A large panel of clinical samples (108 positive and 315 negative for HBsAg) characterized on central lab tests, i.e., ARCHITECT HBsAg, Bio-Rad Genetic Systems EIA, DiaSorin EIA, and bioMerieux Vidas HBsAg (ESM Table S1), were used for the determination of sensitivity and specificity of UCNP-LFIA. The ROC curve of the LFIA with the clinical samples is shown in Fig. 3. The AUC was 0.989. The sensitivity of UCNP-LFIA was 95.4\% (95\% CI 89.5-98.5\%) based on correct determination of 103/108 HBsAg-positive samples and the specificity was $97.1 \%(95 \%$ CI $94.7-98.7 \%)$ based on correct determination of $306 / 315$ negative samples. The same set of samples were tested with a commercial RDT, which resulted in a sensitivity of $87.7 \%$ (95\% CI $79.9-$ $93.3 \%$ ) based on correct determination of 93/106 positive samples and specificity of $99.7 \%$ (95\%CI $98.2-$ $100 \%$ ) based on correct determination of $314 / 315$ negative samples. Two positive samples were run out and thus omitted from testing on commercial RDT. The performance comparison between UCNP-LFIA and commercial RDT is presented in Table 2.

\section{Evaluation of UCNP-LFIA using performance panels and seroconversion panel}

The UCNP-LFIA performance was investigated using commercial performance panels containing extensively characterized samples scoring positive or negative on several central laboratory tests (ESM Table S1). In parallel, the commercial rapid test was evaluated using these panels. The results of evaluation using AccuSet ${ }^{\mathrm{TM}}$ HBsAg Performance Panel and AccuSet'M HBsAg Mixed Titer Performance Panel are shown in Tables 3 and 4, respectively. The UCNP-LFIA detected 20 out of 24 HBsAg-positive samples within the AccuSet ${ }^{\mathrm{TM}} \mathrm{HBsAg}$ Performance Panel (Table 3), whereas conventional RDT detected only 8 out of 24 samples. The UCNP-LFIA recognized 8 out of 10 positive samples from the Mixed Titer Performance Panel (Table 4). In contrast, the conventional RDT could only detect 4 out of 10 positive samples in the Mixed Titer panel. We have also used a seroconversion panel to study the performance of the developed test in early infection cases. In the seroconversion panel (Table 5), samples are collected from a single donor at different time points in the early stage of HBV infection. The developed UCNP-LFIA detected HBsAg seroconversion at day 14 , which was earlier than the commercial rapid test (Table 5).

\section{Evaluation of UCNP-LFIA using HBV genotype panels}

There is a concern that genetic variants of HBV affect the sensitivities of HBsAg assays or even escape the detection from assays relying on monoclonal antibodies only [32-34]. Genetic variation in HBsAg has been 
Table 6 Evaluation of the developed UCNP-LFIA with HBV genotype panels

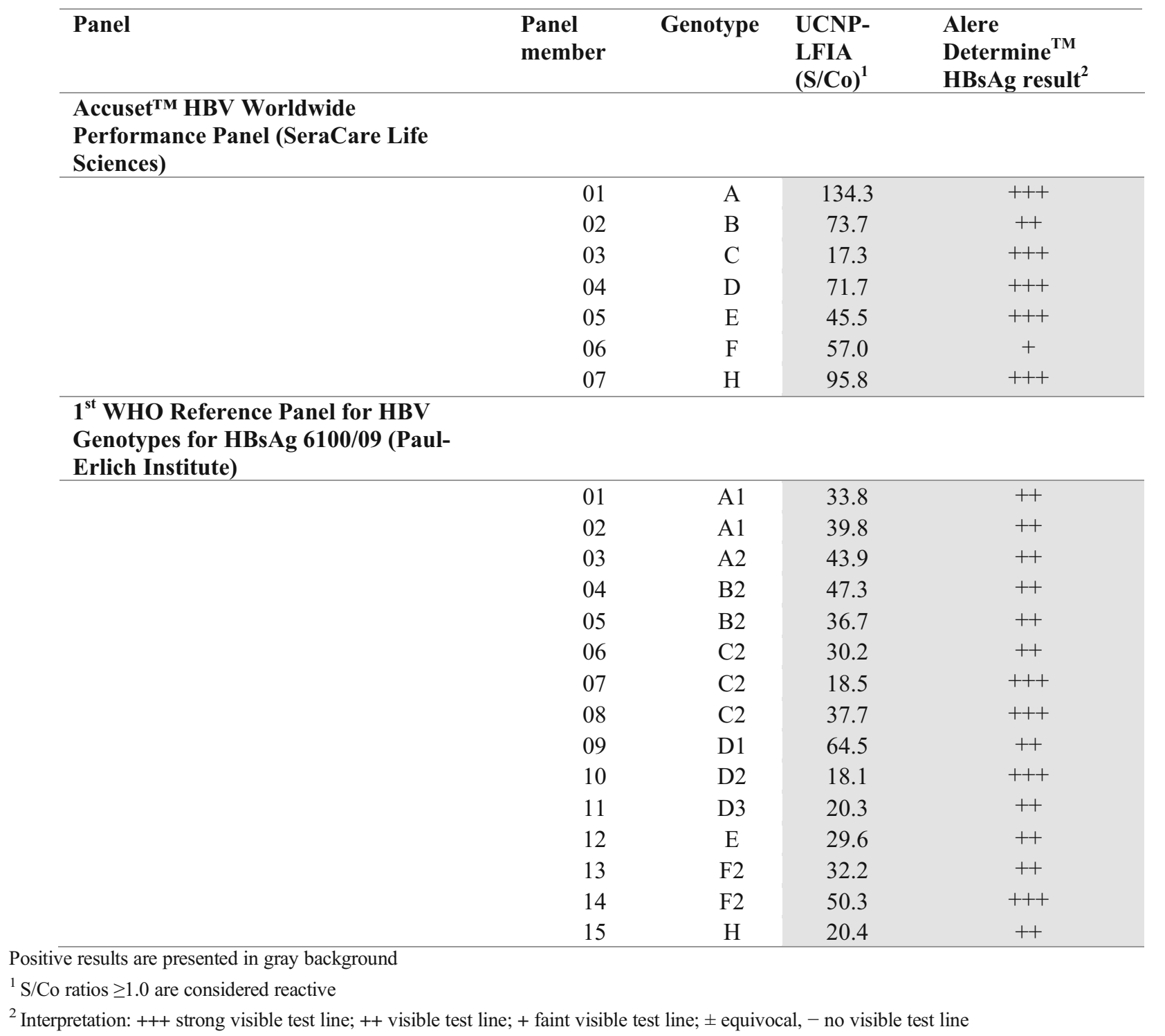

demonstrated to affect the sensitivities of HBsAg detection assays [35] and therefore there is a need to use pairs of antibodies that detect HBsAg from all major HBV genotypes/variants. In the UCNP-LFIA, three non-
Fig. 4 UCNP-LFIA stability at $37^{\circ} \mathrm{C}$. The stability of the strips was tested at 7 time points during 50 days with $\mathrm{HBsAg}$ concentrations $0 \mathrm{ng} / \mathrm{ml}$ (solid line), $0.5 \mathrm{ng} / \mathrm{ml}$ (dashed line), and $5 \mathrm{ng} / \mathrm{ml}$ (dotted line) in serum. Error bars represent the standard deviation of 3 replicates

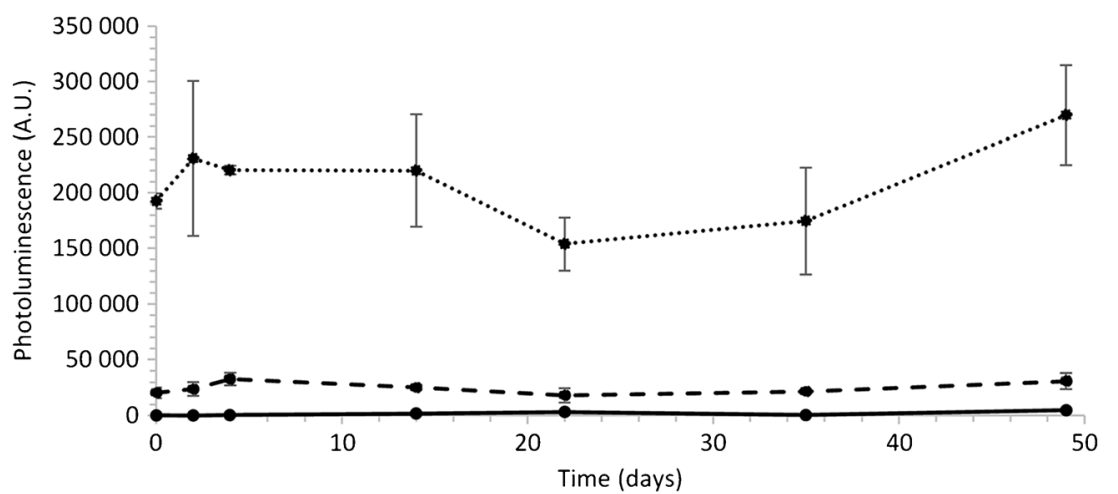


Fig. 5 Correlation of UCNPLFIA and Abbott Architect HBsAg signal-to-cutoff ratios (S/Co) with the AccuSet HBsAg Performance Panel samples. $R^{2}=$ 0.87

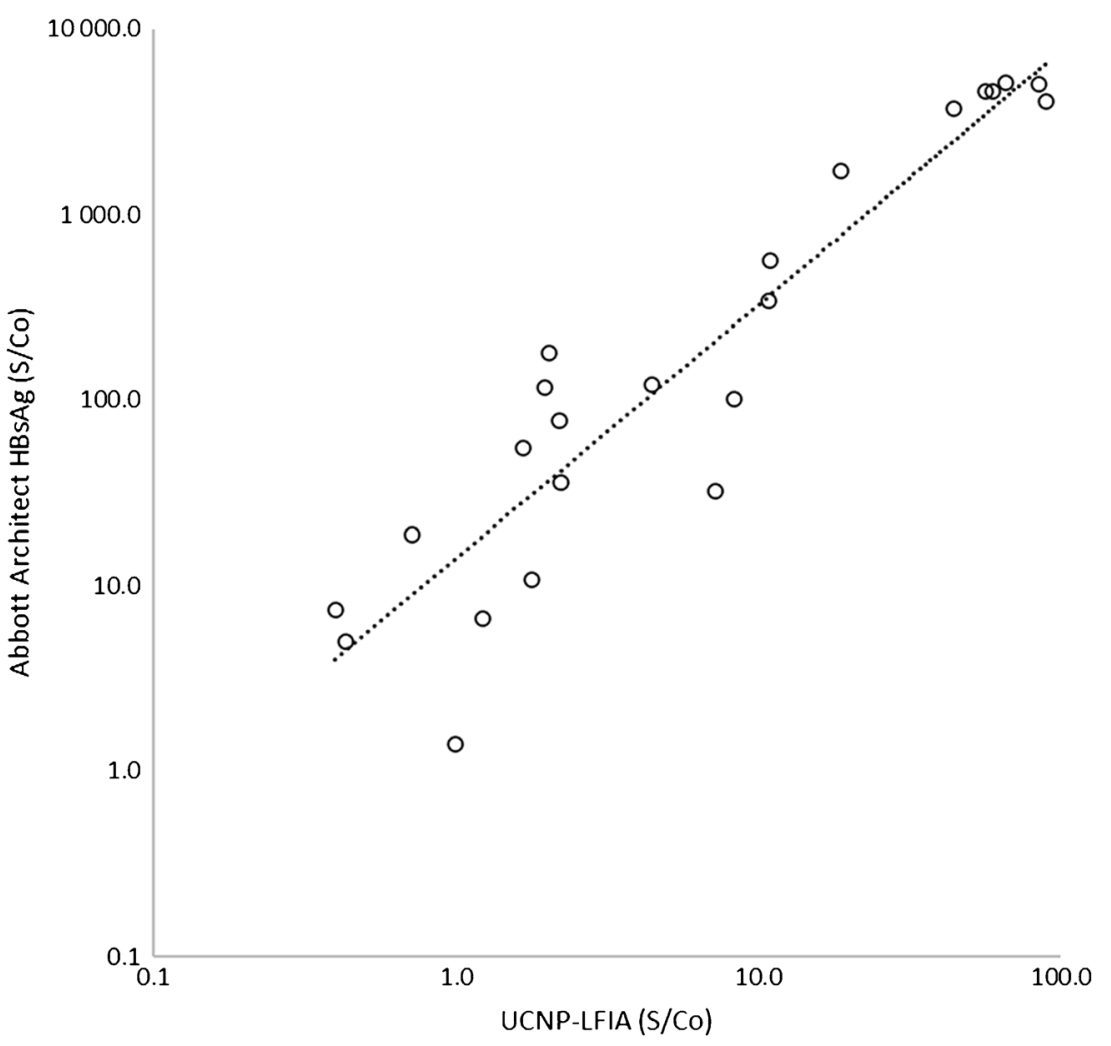

competing monoclonal capture antibodies were applied alongside the monoclonal tracer antibody that was selected based on the binding with the major HBV genotypes (see ESM, Figs. S4 and S5 and Tables S2 and S3). The detection of HBV genotype variants by the developed LFIA was ensured by evaluating the assay with the 1 st WHO international reference panel for HBV genotypes for HBsAg assays (6100/09) and the AccuSet ${ }^{\text {TM }} \mathrm{HBV}$ worldwide performance panel. The results of the genotype detection are shown in Table 6. The UCNP- LFIA as well as the commercial RDT were able to detect all the HBV genotypes.

\section{Stability of UCNP-LFIA strips}

A stability study of the UCNP-LFIA strips was performed at $37{ }^{\circ} \mathrm{C}$ for 50 days. The strips were tested at 7 time points during the study period. The data suggest that the test is stable with no significant change in the performance even for the lower concentration of HBsAg tested (Fig. 4). The LFIA strips generally have a good shelf-life and are often stored at room temperature. The endurance in varying conditions, which may occur during transportation and storage, allows the delivery of the test to the end-users in low-resource settings [36].

\section{Photoluminescence measurement reproducibility}

As the UCNP-LFIA requires a reader device to read the strip, it is essential to analyze the reproducibility in the photoluminescence measurement. For this purpose, we have performed 15 repeat measurements of the same strips with varying amounts of analytes and found coefficients of variation $(\mathrm{CV})$ of $2.8 \%, 2.0 \%$, and $1.8 \%$ for strips run with $0,0.5$, and $5 \mathrm{ng} / \mathrm{ml} \mathrm{HBsAg}$, respectively (ESM Fig. S9). This result suggests that the reader device can provide consistent photoluminescence readout. We have also compared the performance of a benchtop UCNP reader with a battery-operated portable UCNP reader and found similar sensitivity for both the reader for measuring signal from UCNPs on the strip (ESM Fig. S10).

\section{Correlation between UCNP-LFIA and Architect S/co ratios}

As the UCNP technology enables the analyte quantification in LFIA format [14, 16], correlation in S/Co ratios of the developed UCNP-LFIA and Abbott Architect (automated chemiluminescent immunoassay) was examined, and it was found to be reasonable $\left(R^{2}=0.87\right)$ (Fig. 5). Quantitative measurement of HBsAg can be used for guiding therapeutic indications [37], particularly in LMICs where methods to detect and 
quantify HBV DNA are often unavailable. As UCNP technology uses a reader device and results are quantifiable, the developed UCNP-LFIA may also find its utility in semiquantitative determination of HBsAg concentration.

\section{Conclusions}

In LMICs, RDTs are often used instead of EIAs as RDTs are low cost and do not require much infrastructure and trained personnel. Due to this, there is a need for highly sensitive RDTs detecting HBsAg, particularly for the screening of donated blood [3]. In this work, we developed a UCNP-LFIA, which is more sensitive than the commercial visually read RDT. In the future, the assay will be evaluated in clinical settings, with freshly drawn patient samples, using a batteryoperated reader device feasible for point-of-care use to evaluate the true performance of the UCNP-LFIA. High-sensitivity rapid tests for HBsAg are necessary with the effective vaccination program to eliminate Hepatitis B.

Supplementary Information The online version contains supplementary material available at https://oi.org/10.1007/s00216-020-03055-z.

Funding This work was supported by the Wellcome Trust, UK, and BIRAC, India through an Affordable Healthcare in India award, ref. \# 106295/A/14/Z.

Data availability Not applicable.

\section{Compliance with ethical standards}

Ethical approval The use of the samples in this study was approved by the Ethical Committee of the Hospital District of Southwest Finland (Decision T012/011/18).

Conflict of interest DK is a major shareholder in Arrow weighing systems Pvt. Ltd. which is a joint assignee for a patent on a batterypowered UCNP reader device. The other authors declare that they have no conflict of interest.

\section{Consent to participate Not applicable.}

Consent for publication Not applicable.

Code availability Not applicable.

Open Access This article is licensed under a Creative Commons Attribution 4.0 International License, which permits use, sharing, adaptation, distribution and reproduction in any medium or format, as long as you give appropriate credit to the original author(s) and the source, provide a link to the Creative Commons licence, and indicate if changes were made. The images or other third party material in this article are included in the article's Creative Commons licence, unless indicated otherwise in a credit line to the material. If material is not included in the article's Creative Commons licence and your intended use is not permitted by statutory regulation or exceeds the permitted use, you will need to obtain permission directly from the copyright holder. To view a copy of this licence, visit http://creativecommons.org/licenses/by/4.0/.

\section{References}

1. Global Hepatitis Report 2017. Geneva: World Health Organization. 2017.

2. Hepatitis B Factsheet. World Health Organization. https://www. who.int/news-room/fact-sheets/detail/hepatitis-b. Accessed 11 Feb 2020

3. Allain J-P, Opare-Sem O. Screening and diagnosis of HBV in lowincome and middle-income countries. Nat Rev Gastroenterol Hepatol. 2016;13:643-53. https://doi.org/10.1038/nrgastro.2016. 138.

4. Tang LSY, Covert E, Wilson E, Kottilil S. Chronic hepatitis B infection a review. JAMA. 2018;319:1802-13.

5. Lemoine M, Shimakawa Y, Njie R, Taal M, Ndow G, Chemin I, et al. Acceptability and feasibility of a screen-and-treat programme for hepatitis B virus infection in the Gambia: the Prevention of Liver Fibrosis and Cancer in Africa (PROLIFICA) study. Lancet Glob Health. 2016;4:e559-67. https://doi.org/10.1016/S2214109X(16)30130-9.

6. Trépo C, Chan HLY, Lok A. Hepatitis B virus infection. Lancet. 2014;384:2053-63. https://doi.org/10.1016/S0140-6736(14) 60220-8.

7. Mbanya D. Use of quality rapid diagnostic testing for safe blood transfusion in resource-limited settings. Clin Microbiol Infect. 2013;19:416-21. https://doi.org/10.1111/1469-0691.12184.

8. Scheiblauer H, El-Nageh M, Diaz S, Nick S, Zeichhardt H, Grunert H-P, et al. Performance evaluation of 70 hepatitis B virus (HBV) surface antigen (HBsAg) assays from around the world by a geographically diverse panel with an array of HBV genotypes and HBsAg subtypes. Vox Sang. 2010;98:403-14. https://doi.org/10. 1111/j.1423-0410.2009.01272.x.

9. WHO performance evaluation acceptance criteria for $\mathrm{HBsAg}$ in vitro diagnostics in the context of WHO Prequalification. https:/www.who.int/diagnostics_laboratory/evaluations/hepb/ 161125 _who_performance_criteria_hbsag_ivd.pdf?ua $=1$. Accessed 11 Feb 2020.

10. Gasperino D, Baughman T, Hsieh HV, Bell D, Weigl BH. Improving lateral flow assay performance using computational modeling. Annu Rev Anal Chem. 2018;11:219-44. https://doi. org/10.1146/annurev-anchem-061417-125737.

11. Gordon J, Michel G. Analytical sensitivity limits for lateral flow immunoassays. Clin Chem. 2008;54:1250-1.

12. Juntunen E, Myyryläinen T, Salminen T, Soukka T, Pettersson K. Performance of fluorescent europium(III) nanoparticles and colloidal gold reporters in lateral flow bioaffinity assay. Anal Biochem. 2012;428:31-8. https://doi.org/10.1016/J.AB.2012.06.005.

13. Leonardi GP, Wilson AM, Zuretti AR. Comparison of conventional lateral-flow assays and a new fluorescent immunoassay to detect influenza viruses. J Virol Methods. 2013;189:379-82. https://doi. org/10.1016/J.JVIROMET.2013.02.008.

14. Corstjens PLAM, van Lieshout L, Zuiderwijk M, Kornelis D, Tanke HJ, Deelder AM, et al. Up-converting phosphor technology-based lateral flow assay for detection of Schistosoma circulating anodic antigen in serum. J Clin Microbiol. 2008;46: 171-6. https://doi.org/10.1128/JCM.00877-07.

15. Hampl J, Hall M, Mufti NA, Yao YM, MacQueen DB, Wright WH, et al. Upconverting phosphor reporters in immunochromatographic assays. Anal Biochem. 2001;288:176-87. https://doi.org/10.1006/ ABIO.2000.4902.

16. Corstjens PLAM, de Dood CJ, van der Ploeg-van Schip JJ, Wiesmeijer KC, Riuttamäki T, van Meijgaarden KE, et al. Lateral 
flow assay for simultaneous detection of cellular- and humoral immune responses. Clin Biochem. 2011;44:1241-6. https://doi. org/10.1016/J.CLINBIOCHEM.2011.06.983.

17. Juntunen E, Arppe R, Kalliomäki L, Salminen T, Talha SM, Myyryläinen T, et al. Effects of blood sample anticoagulants on lateral flow assays using luminescent photon-upconverting and Eu(III) nanoparticle reporters. Anal Biochem. 2016;492:13-20. https://doi.org/10.1016/J.AB.2015.09.009.

18. He H, Liu B, Wen S, Liao J, Lin G, Zhou J, et al. Quantitative lateral flow strip sensor using highly doped upconversion nanoparticles. Anal Chem. 2018;90:12356-60. https://doi.org/10.1021/acs. analchem.8b04330.

19. Gong Y, Zheng Y, Jin B, You M, Wang J, Li XJ, et al. A portable and universal upconversion nanoparticle-based lateral flow assay platform for point-of-care testing. Talanta. 2019;201:126-33. https://doi.org/10.1016/j.talanta.2019.03.105.

20. Ji T, Xu X, Wang X, Zhou Q, Ding W, Chen B, et al. Point of care upconversion nanoparticles-based lateral flow assay quantifying myoglobin in clinical human blood samples. Sensors Actuators B Chem. 2019;282:309-16. https://doi.org/10.1016/j.snb.2018.11. 074.

21. Li L, Zhou L, Yu Y, Zhu Z, Lin C, Lu C, et al. Development of upconverting phosphor technology-based lateral-flow assay for rapidly quantitative detection of hepatitis B surface antibody. Diagn Microbiol Infect Dis. 2009;63:165-72. https://doi.org/10.1016/j. diagmicrobio.2008.10.020.

22. Haase M, Schäfer H. Upconverting nanoparticles. Angew Chem Int Ed. 2011;50:5808-29. https://doi.org/10.1002/anie.201005159.

23. Riuttamäki T, Soukka T. Upconverting phosphor labels for bioanalytical assays. In: Advances in chemical bioanalysis. Cham: Springer International Publishing; 2013. p. 155-204.

24. Greenfield EA. Polyethylene glycol fusion for hybridoma production. Cold Spring Harb Protoc. 2018;2018:191-6. https://doi.org/ 10.1101/pdb.prot103176.

25. Das S, Peck RB, Barney R, Jang IK, Kahn M, Zhu M, et al. Performance of an ultra-sensitive Plasmodium falciparum HRP2based rapid diagnostic test with recombinant HRP2, culture parasites, and archived whole blood samples. Malar J. 2018;17:118. https://doi.org/10.1186/s12936-018-2268-7.

26. Lin Y-H, Wang Y, Loua A, Day G-J, Qiu Y, Nadala ECB, et al. Evaluation of a new hepatitis B virus surface antigen rapid test with improved sensitivity. J Clin Microbiol. 2008;46:3319-24. https:// doi.org/10.1128/JCM.00498-08.
27. WHO guidelines on hepatitis B and C testing. Geneva: World Health Organization. 2017.

28. Khuroo MS, Khuroo NS, Khuroo MS. Accuracy of rapid point-ofcare diagnostic tests for hepatitis B surface antigen - a systematic review and meta-analysis. J Clin Exp Hepatol. 2014;4:226-40. https://doi.org/10.1016/J.JCEH.2014.07.008.

29. Song LW, Wang YB, Fang LL, Wu Y, Yang L, Chen JY, et al. Rapid fluorescent lateral-flow immunoassay for hepatitis B virus genotyping. Anal Chem. 2015;87:5173-80. https://doi.org/10. 1021/ac504832c.

30. An BG, Kim HR, Kang MJ, Park JG, Chang YW, Pyun JC. Chemiluminescent lateral-flow immunoassays by using in-situ synthesis of CdS NW photosensor. Anal Chim Acta. 2016;927:99106. https://doi.org/10.1016/j.aca.2016.04.048.

31. Chen X, Leng Y, Hao L, Duan H, Yuan J, Zhang W, et al. Selfassembled colloidal gold superparticles to enhance the sensitivity of lateral flow immunoassays with sandwich format. Theranostics. 2020;10:3737-48. https://doi.org/10.7150/thno.42364.

32. Harrison TJ. Current issues in the diagnosis of hepatitis B and C virus infections. Clin Diagn Virol. 1996;5:187-90. https://doi.org/ 10.1016/0928-0197(96)00220-6.

33. Alavian SM, Carman WF, Jazayeri SM. HBsAg variants: diagnostic-escape and diagnostic dilemma. J Clin Virol. 2013;57: 201-8. https://doi.org/10.1016/J.JCV.2012.04.027.

34. Carman WF. The clinical significance of surface antigen variants of hepatitis B virus. J Viral Hepat. 1997;4:11-20. https://doi.org/10. 1111/j.1365-2893.1997.tb00155.x.

35. Ireland JH, O'donnell B, Basuni AA, Kean JD, Wallace LA, Lau GKK, et al. Reactivity of 13 in vitro expressed hepatitis B surface antigen variants in 7 commercial diagnostic assays. 2000. https:// doi.org/10.1053/he.2000.6407.

36. Jorgensen P, Chanthap L, Rebueno A, Tsuyuoka R, Bell D. Malaria rapid diagnosNc tests in tropical climates: the need for a cool chain. Am J Trop Med Hyg. 2006;74(5):750-4. https://doi.org/10.4269/ ajtmh.2006.74.750.

37. Cornberg M, Wong VW, Locarnini S, Brunetto M, Janssen HLA, Chan HL. The role of quantitative hepatitis B surface antigen revisited. J Hepatol. 2017; 66(2):398-411. https://doi.org/10.1016/ j.jhep.2016.08.009.

Publisher's note Springer Nature remains neutral with regard to jurisdictional claims in published maps and institutional affiliations. 